\title{
A Symbiotic Link Between Music, Movement, and Social Emotional Learning: Mindful Learning in Early Learners
}

\author{
Matt Yanko and Priscilla Yap
}

\begin{abstract}
In the following study we investigate how young learners engage with music and movement to illustrate their understandings and connections to nature. We discover a symbiotic relationship between the performing arts, Social Emotional Learning, and Mindful Learning over the course of six months, and examine the potentials and constraints of this harmonization. Results from this study show that learning in a co-constructivist setting, which allows opportunities for reflective listening, choice, intentional focus, and feedback, supports the development of behavioural and emotional abilities, and empowers students to delve deeper into their connections with nature through composing abstract music and movement pieces.
\end{abstract}

\section{A Prelude to Our Inquiry}

David Abram (1996) posits: "The landscape as I directly experience it is hardly a determinate object; it is an ambiguous realm that responds to my emotions and calls forth feelings from me in turn" (p. 33). Abram elucidates that our surroundings are alive, and he entices us to embrace our feelings and foster a relationship with it. Accordingly, many educators provide opportunities for their students to engage with the natural world through play, exploration, wonder, and imagination. While participating in such experiences, learners are encouraged to represent their feelings, values, and understandings. However, the conventional means of communicating through pencil and paper can become a restrictive, one-dimensional medium for meaning making, as it hinders the livingness that resides in the lived experiences of children and falls contradictory to the livingness of the natural world. Therefore, we turn to the performing arts, and, in particular, music and movement, as living media for meaning making. Music and movement can offer learners a means to interpret and express their experiences in the natural world, as the arts provide a platform for children and teachers to perceive things in ways other than they are normally seen (Eisner, 2002, p. 83).

When students apply music and movement as a way to illustrate connections, values, and understandings, they participate in co-constructivist processes that evoke subjective vulnerabilities, feelings, and ideas. In those types of experiences, educators need to provide opportunities for children to engage with purposeful focus and listening, and to develop openness to others' perspectives. In doing so, those students also require skills such as solving conflicts, being attentive, following directions, and managing emotions. Thus, as young learners engage with music and movement as media for meaning making, such experiences necessitate an acquisition of behavioural and emotional capabilities, and educators can turn to Mindfulness and Social Emotional Learning (SEL) to foster those abilities. 
Mindfulness has been described as "the awareness that emerges through paying attention on purpose, in the present moment, and nonjudgmentally to the unfolding of experience moment by moment" (Kabat-Zinn, 2003, p. 145). Activities such as music and dance can cultivate awareness, attention, and intention, as well as empower students to express themselves freely to create something that is guided from within. SEL involves processes through which a person develops fundamental emotional and social competencies to recognize and manage emotions, develop concern and care for others, establish positive relationships, make responsible decisions, and handle challenging situations constructively (Weissberg, Payton, O'Brien, \& Munro, 2007, p. 417). Educators can orchestrate SEL and mindful learning experiences together, since both initiatives focus on educating the whole child through the development of positive self, moral, social, and emotional understanding (Lawlor, 2016).

To date, there is minimal research that has examined the integration of mindful learning and SEL programming. Thus, we seek to fill a void in research concerning the harmonization of mindfulness and SEL within a framework of the performing arts. We examine the struggles, benefits, and extent to which children's meaning making through music and movement provides a platform for the co-development of the attributes associated with mindful learning and SEL. This study occurs over the course of six months and involves 22 Grade 1 students.

\section{The Pulse of Our Story}

Stories readily incorporate themselves into our felt experiences-in hearing or telling the story we vicariously live it, and the travails of its characters embed themselves into our own flesh (Abram, 1996, p. 77). Contemporary ethnographic methods that bring storytelling into the inquiry process illustrate new ways of writing that re-conceptualizes teaching and learning. In the current investigation, we employ an autoethnographic storying approach (Ellis, 2004) that empowers us to create stories written in a creative nonfictional style based on empirical data-observations, notes, and artefacts. In doing so, we pursue essences and meanings, rather than portraying and representing precise facts. Within the context of music education, autoethnographies have been used to shed light on the experiences of students and teacher (Gouzouasis \& Yanko, 2018a, 2018b; Yanko, 2019). The classroom and outdoors are more than mere settings, as they contribute meaning to their inhabitants and embody the fabric of their storied experience-places develop their significance or identity through stories about what has happened there. Thus, our stories are written from the perspective of the teacher(s), from the self or auto, but are also composed in dialogue with those involved in the learning experience. We interpret the prefix "auto" through Greek language underpinnings to afford a consideration of the joining of the self, him and her, them, those, they, and that (Gouzouasis \& Ryu, 2015). We engage with autoethnography as a means of writing critical reflections based on concrete details, vivid descriptions, personal feelings, and emotions (Ellis \& Bochner, 2000). Lesa Lockford (2002) describes this emotionality and sensitivity in alternative ethnographic texts as "stories that move [her] to stillness...call[ing] [her] to take pause, to reflect, to feel" (p. 76). Thus, this framework empowers us to evoke our students to reflect on their behavioural and emotional development as the inquiry progresses. 


\section{Grounding Literature}

We reflect on literature that supports music and movement as a means for meaning making, as the abstract nature and poetic capabilities of music can support students to express their understandings of their lived experiences. For instance, the practice of soundscape composition draws on perceptual constructs of the acoustic landscape, whereby the original sounds must stay recognizable and the listener's contextual and symbolic associations should be invoked for a piece to be a soundscape composition (Truax, 2008, p. 105). We also seek guidance from a previous study of ours where young students used soundscape composition as a means to illustrate their understandings, values, and emotional connections to landmarks in their city (Yanko, 2019). With the above in mind, the students in the current study are encouraged to incorporate natural sounds and materials alongside traditional instruments to illustrate their understandings and connections to nature.

Children naturally play and make meaning through story-as human beings we live storied lives. Snowber (2019) extends the idea of story to include body narratives, where our body and all the senses are a source of knowledge, learning, wisdom, and material for creation. We encourage our students to engage with creative movements as a means to illustrate understanding through basic elements of movement, like body, space, and effort (Laban, 1963). Malaguzzi (1998) posits, "symbols have profound associations with emotions, feelings, and many other things that cannot be qualified through observation" (p. 93). In the case of dance, it is a unique language through which individuals can express their feelings, thoughts, and emotions. As the inquiry progresses, we will encourage our students to communicate their connections and meaning making through movement and music, as the performing arts are a living media that can illuminate the livingness that resides in the lived experiences of these children with nature.

Mindfulness is a human capacity, and, like other capacities, it can be honed and sharpened, or it can be dulled. When we engage in learning experiences that evoke mindful states, we recognize that there is more than one perspective on the information given. We choose from among those perspectives, and reflect on how our perceptions structure experience on the assumption that they are more malleable and susceptible to individual control than that which is apparent at first glance (Langer, 2016). Thus, we avoid narrow mind-sets that limit our potentials, and recognize the arts as a means to navigate roadblocks and attain a flexible state of mindfulness. The arts play a role in meaning making through reflection, awareness, and transformation, leading to a heightened and focused relationship between the individual and what was previously unseen (Eisner, 2002).

Being mindful is a simple act of drawing novel distinctions, which can lead us to greater sensitivity to context and perspective, and ultimately to greater control over our lives (Langer, 2000). Ellen Langer refers to that practice as "mindful learning." Langer's construct of mindful learning supports the proposition that each music making experience should be seen as novel, potentially exciting, and always providing an opportunity for rich experiences. Research by Langer, Russell, and Eisenkraft (2009) compared two orchestral performances of Brahms' Symphony No. 1. In that study, the control group focused on re-creating a previous best performance, while the intervention group was instructed to draw on novel distinctions within a boundaried, task-specific focus. Findings revealed that the audience and 
musicians reported more enjoyment from the mindfulness performance in comparison to the control group. In addition, dance and creative movements can also support the construct of mindful learning because they require focus on the present moment. In a study by Pinniger, Brown, Thorsteinsson, and McKinley (2012), participants engaged in learning the tango-an intense synchronized dance that requires focus, trust, and support between partners as they walk backwards and forwards. Results found the tango to be an effective strategy to reduce participants' levels of depression and increase their wellness.

There are five components of SEL: self-awareness, social awareness, responsible decision-making, self-management, and relationship skills (CASEL, 2003). Research recognizes that early childhood is an ideal time to begin SEL development (Denham, Brown, \& Domitrovich, 2011), and a small but growing body of literature indicates that children's involvement in the arts can result in positive gains in SEL (Rooney, 2004). Research in music and SEL shows that investing time and effort that results in a successful performance, can also foster self-esteem, self-confidence, determination, and emotional expression (Croom, 2012; Hallam, 2010; Lund \& Kranz, 1994). In the context of elementary school music, Jacobi (2012) explored the development of children's socio-emotional skills and posits that cooperation, sense of belonging, empathy, and active listening can be fostered through music. Also, a study by Pereira and Marques-Pinto (2018) examined the social and emotional skills of middle school students who participated in a dance program, whereby the results revealed the social and emotional needs of the students, and their desire to engage with interesting music and dance moves.

\section{Six Autoethnographic Vignettes: A Narrative Interlude}

The following autoethnographic vignettes depict the journey of Grade 1 students as they explore, wonder, investigate, and connect with the ecosystem of a creek near their school. These stories weave together as a narrative to illustrate their meaning making through music and movement, and how engagement with the performing arts can scaffold growth in mindfulness and the development of social emotional skills.

\section{Vignette One: Wonders in the Water}

As the children, Ms. Yap, and Mr. Yanko arrive at the creek, they stop at a rickety old bridge, and everyone huddles together.

"Wow! The water sounds fast, like a rushing tap," exclaims Rosanna.

"Look! There's a family of bugs dancing on the water," adds Luisa, as she mimics their jagged movements with her arms.

From the bridge, the children venture into a forested area with tall mossy trees and prickly blackberry bushes. They follow a path that leads to a smaller trickling section of the creek.

"The water by the bridge was way louder," claims Paolo.

"Shhh! Stop it! Stop talking! I can't hear it," whines Rohan.

It takes a while, but everyone eventually quiets down to focus on listening. 


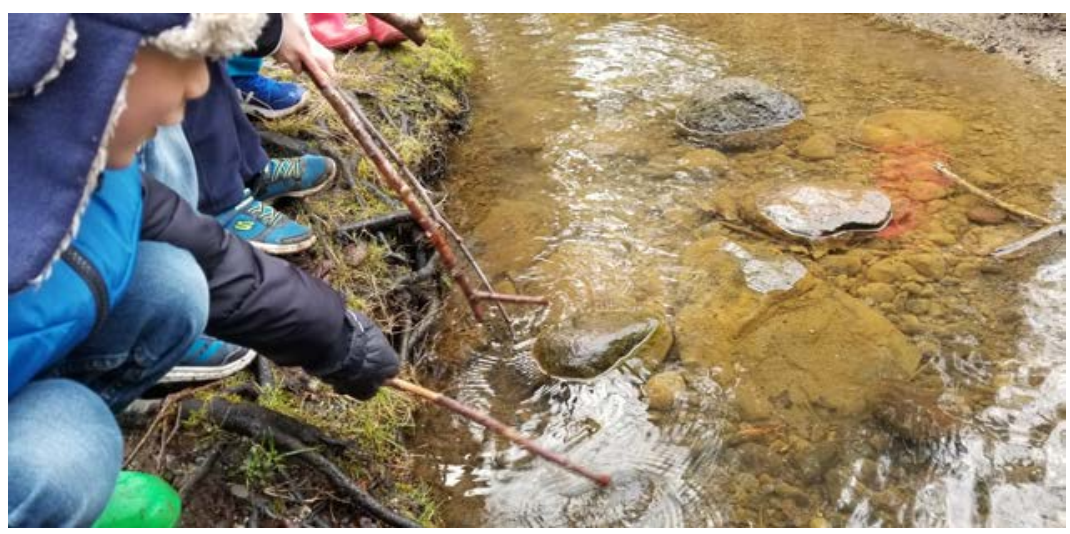

Fig. 1: Children using sticks to explore the water

Afterwards, they follow the course of the creek and stop where the water expands to a pool. Some of the children notice a pile of sticks and use them to explore the water.

"What are you doing with those branches?" Mr. Yanko asks.

"I'm seeing the sounds of these," Crystal replies as she dabs two sticks.

"Does the size of the stick make a difference?"

She whacks the large branch on the water, "This one is loud. The other isn't loud, maybe because it isn't big."

After the pool, the creek flows into a sewer pipe. However, the children don't have time to explore that area. It is time to head back to school.

Later that day in the classroom, the children organize gathered leaves, pinecones, rocks, flowers, and sticks from the creek. While doing so they discover a slug on a leaf and decide to make it a class pet. They name it Slugly.

\section{Vignette Two: Re-creating the Timbres of the Creek}

The following Friday we share an autoethnographic learning story (Yanko \& Gouzouasis, 2019; Gouzouasis \& Yanko, 2018b) about the experience at the creek. In the midst of reading the story, the children spontaneously break out in body-percussion to revive the sonic elements of their explorations. Ms. Yap works with their sound effects and draws out the descriptive words in the story. The students make swishing sounds with their mouths and drum their hands on the carpet. After the story, they begin to explore and create with the gathered materials from the creek.

Mr. Yanko notices two girls shaking a large cylinder vigorously.

"What are you making?"

"It's a shaking-creek-thingy," Rosanna states, as she and Crystal shake it together.

"When we are at the creek, we don't just hear water," Rosanna says, as she takes off the lid.

"Look inside. There are rocks, sticks, and this green stuff. All of the creek makes the sounds that we hear, not just the water." 
Mr. Yanko comments, "It's like a symphony that harmonizes the water with other elements in the creek. I like that idea." Rosanna grabs a fistful of sand and plunks it into her instruments. They shake it. Both partners nod in affirmation. She adds a few pebbles and shakes it again.

"Nope, not right!" She states and takes a few out.

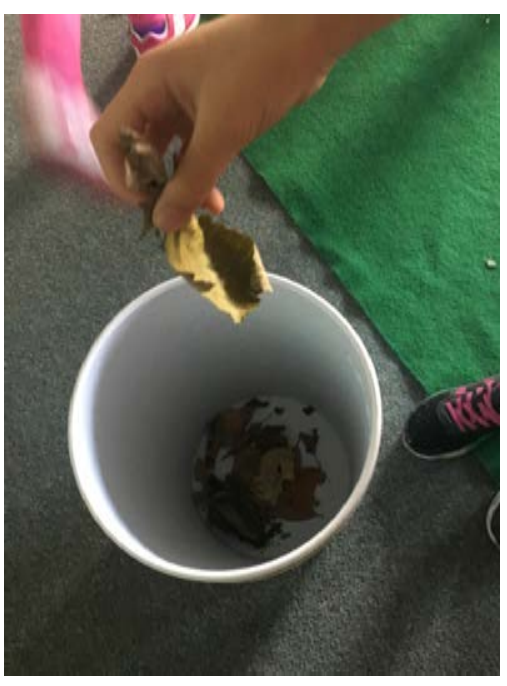

Fig. 2: Children putting in materials gathered from the creek

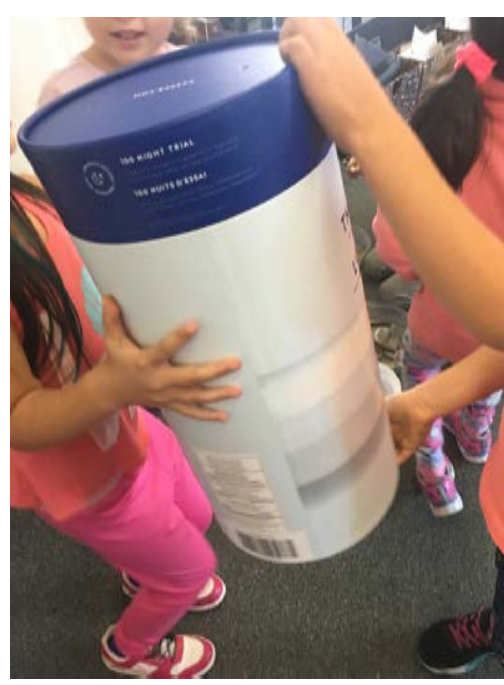

Fig. 3: Children shaking a large cylinder

In the meantime, Ms. Yap is outside with students exploring water in a large tub.

Paolo taps a rhythmic ostinato on the rim of the tub, while Alex rapidly swirls a stick to create a long whirlpool note in the water.

"What's this song about?" Ms. Yap inquires.

Alex replies, "It's a water song. We have different beats for different parts of the creek."

"Stop...Stop tapping! Let me get closer! It's my turn you guys." Calvin shouts and pushes his way to the tub. He whacks his stick loudly against the water.

Ms. Yap notices this, "Calvin, if you can't hear your friends' music and only your own then you're playing too loud. Try to play your music with a gentle touch."

He concentrates on gently tapping the water while listening and harmonizing with his friends.

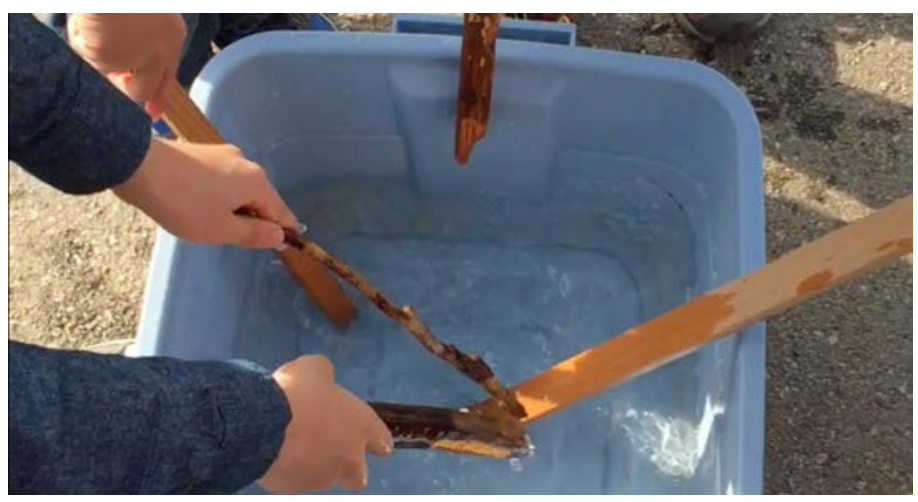

Fig. 4: Sticks in a tub of water 


\section{Vignette Three: Meaning Making Through Movement}

Over the next weeks, the students begin to incorporate movement into their projects.

Mr. Yanko walks over to a group of students constructing an elaborate set using stumps and various coloured fabrics.

"Mr. Yanko, this is our stage," Pam says.

Simrit explains, "These are the trees and down there is the creek. The sewer is also part of it. We go in it." She giggles and crawls through the hula-hoop.

"This is quite the set. How is your movement part coming along?" Mr. Yanko inquires.

"We move like water: we go up and down," Jennifer states, as she sways her arms and body from side to side and slowly lowers herself to the ground.

"But I want to be a tree, not water!" shouts Rob with frustration.

"No! Everyone needs to be water because there's so much water at the creek," Simrit argues. Jennifer interjects, "Well what if the three of us do water and the two boys do trees. There are lots of tall trees at the creek. If we have too much water it may look like a lake."
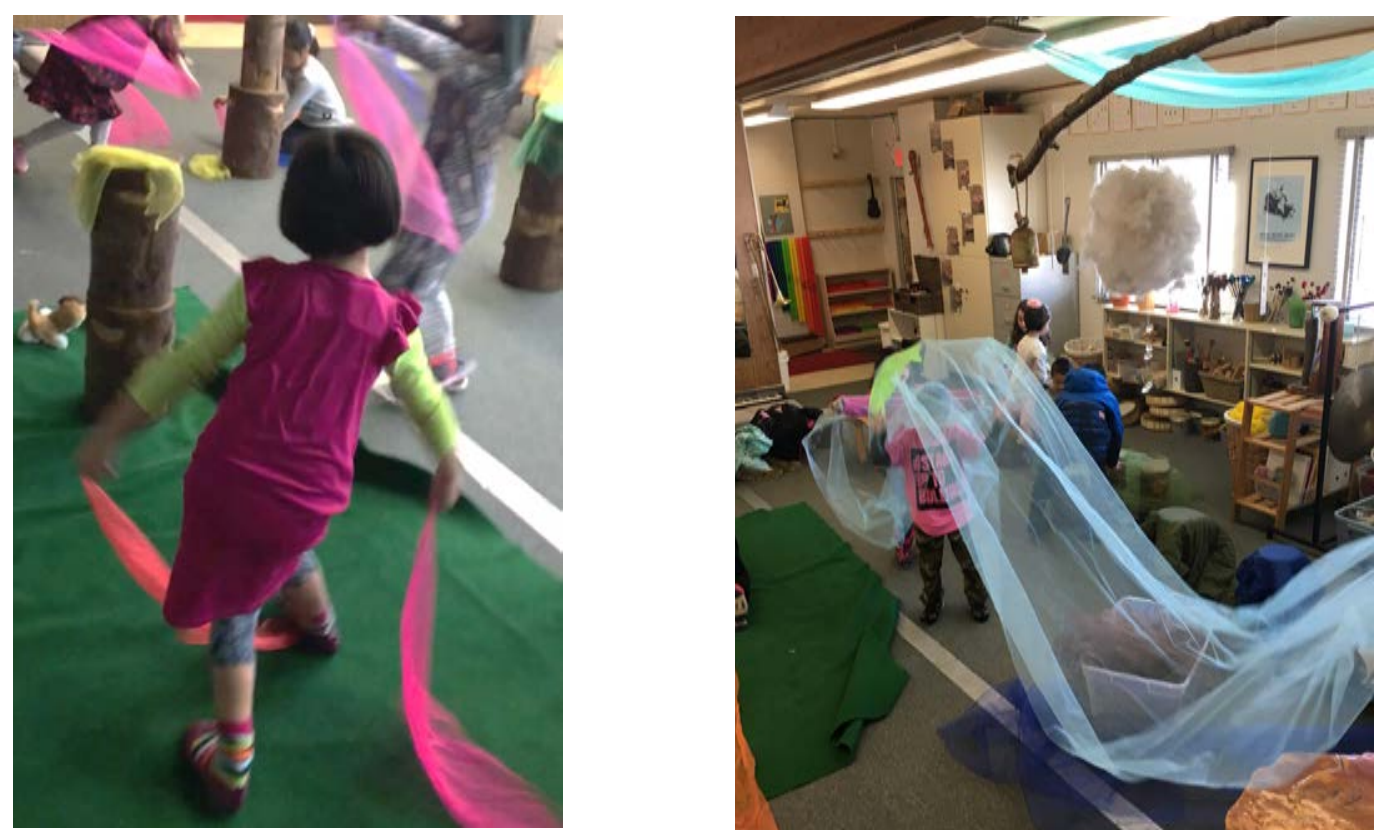

Fig. 5 and Fig. 6: Students dancing with fabrics

Mr. Yanko leaves them as they negotiate their ideas and walks to the middle of the classroom where two students are waving a long piece of fabric.

"It looks like you are creating the creek. Am I right?"

"Yeah, we're the creek," pouts Steve, as he struggles with the fabric. "It is so hard. I'm trying to make waves, but it's...it's so hard to wave at the same time...and...and...all they seem to do is play around." 
"Nicole, are you working on the speed of the waves with Steve?"

She replies, "Kind of, it's hard when the others are moving under it so beautifully. I just want to watch them dance and I forget to wave the fabric with him."

"It takes a lot of focus to be aware of your partners' movements and how and when to move together," Mr. Yanko replies, and leaves them to practice. He walks across the room to join a quartet of boys.

"How's it coming along?"

"Tom is still too orange, we need more brown fabric to cover his shirt," Shawn suggests. "I'Il get more so he looks like a real branch."

"Rohan, you move too much! Rocks don't move like that in water. You should move a bit less. That would look more real and cool," states Alex.

They practice it again with the feedback from each other, and this time they seem to be more in tune with one another.

\section{Vignette Four: A Lament for Slugly}

Slugly is not doing so well and the class decides to return it to the creek. They want to do something special to say farewell and compose a good-bye song with Mr. Yanko. When they arrive at the creek, Ms. Yap takes the leaf that Slugly is resting on and places it in the stream to be carried away. The water slowly pushes the leaf downstream and the children begin to sing their farewell song as Slugly drifts away.

After the lament, Ms. Yap provides the students with two thoughts to guide their exploration time at the creek-to observe things that are the same and to notice what is new and different. The students add a third idea, which is to find a place at the creek that speaks to their hearts.

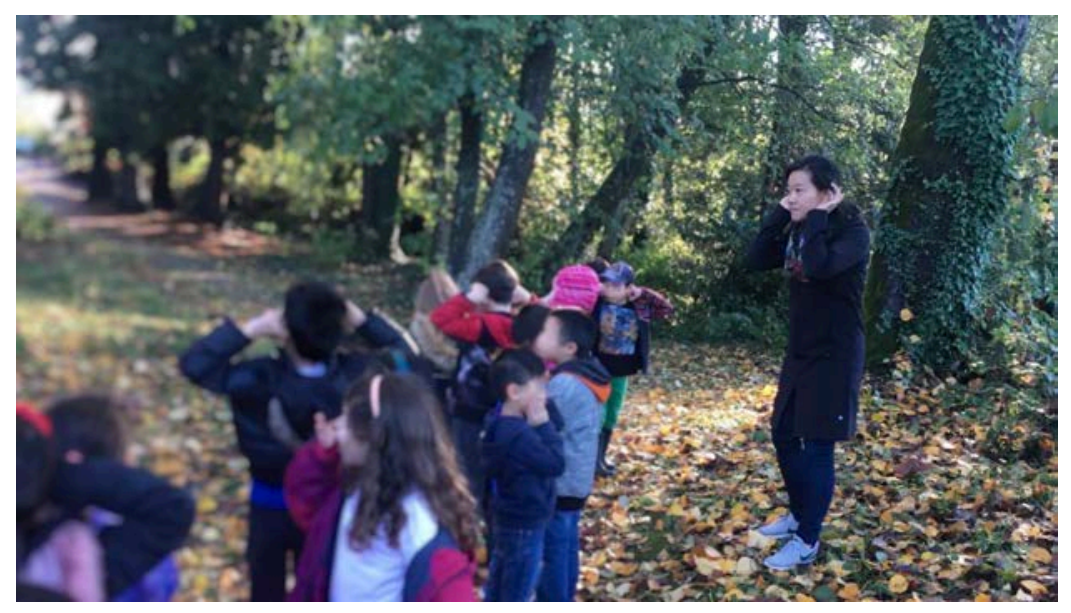

Fig. 7: Hands cupped to ears in forest

To focus their thoughts on the three provocations, Ms. Yap encourages the children to engage with mindful observation skills. "Use your owl-like listening skills to pick up soft sounds. This will help you focus with an alert and open listening, so those sounds won't be missed," she states, as she cups her hands around her ears.

They venture along the creek bank and many students engage with owl-like listening. 
"It's so much louder today!" exclaims Rosanna.

Tom adds, "Yeah, it's like thund..."

"No, it's like a monster," Carrie cuts in.

Nicole trudges her zebra-striped boots against the creek's current, "there's a lot more water. It's swishing really fast!"

Upon returning to school, many students share the part of the creek that speaks to their heart.

"Mine is the deep part of the creek. It was so much fun. The water made me feel like it was a rainy day and I was jumping in puddles," Rohan comments.

"I love the part with whooshing water. I love just being in the water," states Nicole with her hands on her heart.

"I like the creek because the water is soothing, peaceful, and calm," Jennifer adds.

\section{Vignette Five: Places That Speak to Our Hearts}

Today, the students focus on the final touches of their music and movement projects. Mr. Yanko observes the group with the elaborate set. The three girls are working on their water piece. They dip down low, and then back up high to mimic the flow of the creek. As they move towards the hula-hoop, Jennifer shakes a pair of jingle bells, Pam taps a triangle, and Simrit rows a rain stick like paddling a canoe. Off to the side, Trevor and Rob are drumming and playing the thunder tube.

"Last day you were exploring loud and soft sounds, how is that coming along?"

"Soft sounds are inside the sewer and loud are outside. The sewer is a safe place and outside is dangerous," Simrit answers.

"Dangerous for who?"

"Slugly!" She exclaims. "She floated down the creek to her home in the sewer where it's safe."
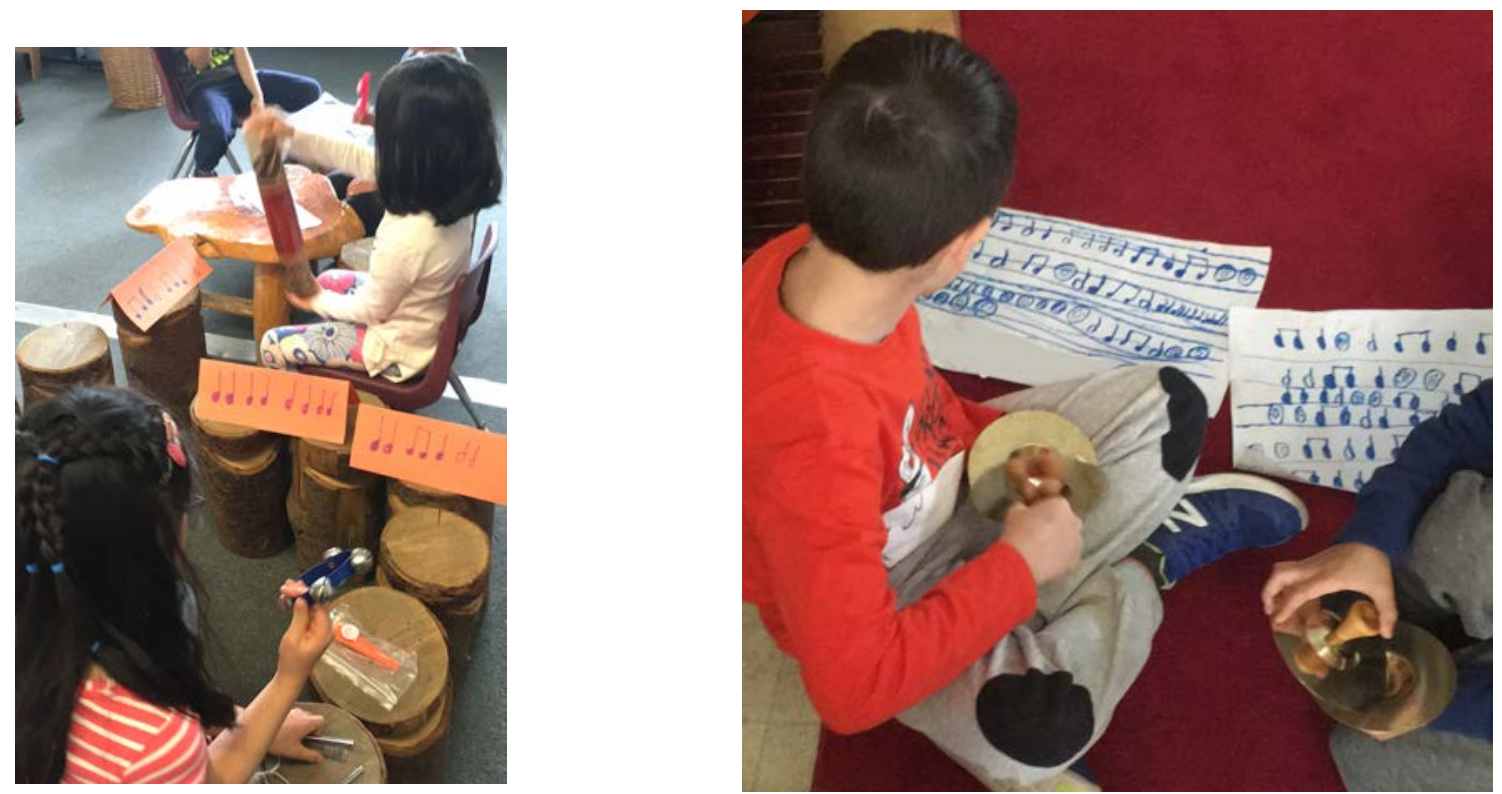

Fig. 8 and Fig. 9: Students playing with instruments 
Mr. Yanko leaves the group to work on their music and walks to the quartet of boys. Three of them have metal cymbals in their hands. "How are you going to make fast water, rocks, and sticks sound different if you are all playing the same instrument?"

"We can show you," states Rohan.

Rohan rubs the flat surface of the cymbals together in small circles. As he nears the end of his music, he nods to Alex and he begins to gently rub the sharp edge of one cymbal against the flat edge of the other. Rohan than cues Tom to join in and he rapidly slices the flat part of one cymbal against the edge of the other.

"Wow! That is an amazing interpretation. I have never seen the cymbals used like that."

\section{Vignette Six: Discourse in the Learning Community}

As the class settles into a semicircle on the carpet, Mr. Yanko begins a discussion, "Some of you said that your music makes you feel a certain way. Who can share a little bit about their music and feelings?"

Crystal thinks for a moment and then answers, "My piano music sounds like rain quietly dripping down. It makes me feel calm."

Tom comments, "I used the metal clappers for the branches crashing by the water. It sounds loud and I like loud sounds."

Jennifer adds, "Well, the music in the sewer was loud and happy sounding because it was a safe place for Slugly. Outside the sewer felt like a danger area. I played quietly because I was far away from the safety of being in the sewer."

Ms. Yap asks, "What is something that was challenging during the project?"

Pam states, "Working together! It took a lot of time to put it together and to agree on good ideas."

Carrie adds, "I noticed that adults are better at talking to each other than kids. When we were doing our movement, it was hard to talk to each other because everyone was saying their ideas at the same time, but when Ms. Yap or Mr. Yanko were helping us, we were better at listening."

Karen adds, "Working together was hard because there's so much interrupting and we need lots of calmness."

Mr. Yanko asks, "Is there anything new that you learned?"

"I learned how to work with my friends," answers Rosanna.

"That things can take lots of time and that you need to work together to make ideas come true. One person can't do it all, it's too hard," states Nicole.

Shawn comments, "I learned how to silently show my friends when to come in with their music."

"Me too, especially when I wanted to talk during the recording part. It was so hard to tell people what to do without words," adds Karen.

\section{Deciphering the Tones of Behavioural and Emotional Abilities}

The autoethnographic vignettes illuminate how the performing arts can provide a framework to support mindful learning and social emotional skills. The stories depict the challenges many young learners 
encounter in their emotional and behavioural development. Fostering a solid social emotional foundation can support them to wholeheartedly engage in mindful learning. Greene (1995) posits,

When we see and hear more we take risks into the unknown. We embark on new avenues for choosing and action where we may gain a sudden sense of new beginnings, and can take an initiative in the light of possibility. (p. 123)

When children are able to strengthen their social emotional skillset, they are better able to engage with mindfulness. This allows them to take risks into the unknown through a focused, yet, flexible, state of mind that allows for new beginnings, possibilities, and understandings. At the onset of the project, we took note of how the students carefully chose their instruments and movements based on a comfort level that directly related to being self-conscious about how their peers would perceive them. As the project progressed, we noticed an intrinsic change and self-assurance in the students, and they were better able to express their ideas through risk taking. This led to a more varied and deeper layer of sound and movement that was not based on how they felt others would perceive them, but on how they wanted to be seen by others. In turn, students were able to appreciate each other's interpretations of music and movement-as a safe and freeing space for expression was created through self-discovery, reflection, and re-visitation.

Mindfulness can be seen as a flexible state of mind through which students actively engaged in the present, notice new things, and are sensitive to context. Experiences in the performing arts that center on inquiry and imagination can scaffold that mindset, as "by imagining, we are enabled to look at things, to think about things as if they were otherwise" (Greene, 2001, p. 65). When children engage with focused imagination, wonder, and exploration in the performing arts, they illuminate aspects of mindful learning, whereby such experiences are seen as novel and potentially exciting. For instance, the ingenuity of the three boys playing the cymbals shows how they circumvent a narrow mind-set and expand beyond the possibilities of preconceived conceptions of how cymbals should be played. Furthermore, it does not matter whether what is noticed is important or trivial, as long as it is new to the viewer. When the children used owl-like listening to focus on changes in the ecosystem, the higher, more forceful water and the abundance of fallen leaves were new and exciting observations.

A significant aspect of mindful learning is being able to make acts of novel distinctions. The second vignette elucidates how the children chose not to work with traditional instruments, but invented new ones using sand, leaves, sticks, and rocks. During that experience, they intensely focused on their creations, engaged with deep listening to the timbres of their new instruments, and delicately tuned them to sound more like the creek's ecosystem. What is interesting about the performing arts in this study is how it empowered the students to engage with a process of categorization, which involves a cognitive process of labeling phenomena and using those labels to make sense of the world around them. In this nontraditional means of communication, they engaged with elements of movement and music as languages to illustrate their understandings.

The abstract nature of movement and music challenged the children to develop a meta-communicative toolbox that assisted them to work through artistic impasses that emerged during the project. In meta-communication, meaning is derived from interaction with others and does not depend on literal 
verbal meaning (Bateson, 1976). As the children worked on creating and performing their pieces, they engaged with meta-communication, whereby they not only listened to their group as a whole, but also to individual parts and interacted with more than one person at the same time-as mentioned by Shawn and Karen who commented on having to learn how to quietly conduct and cue their partners. In such performative learning experiences, students need to develop the ability to step back from what is occurring in the present moment and look at things from a meta-perspective. This requires the capacity to participate in what is going on while observing at the same time. Thus, in performing arts contexts meta-communication can be thought of as a type of mindfulness-in-action, which involves bringing one's complete attention to a present experience on a moment-to-moment basis.

We examine how the five competencies link to the performing arts: to identify and manage emotions, understand other's perspectives, set and achieve goals, foster relationships, and make responsible decisions. The competency of responsible decision-making refers to the ability to identify, analyze, and solve problems. In the group with the elaborate set, the two boys were struggling with their part. Jennifer made an ethical and constructive decision to support her group by not criticizing them. She observed without judgment and offered to switch parts based on awareness and care. This type of consciousness lends itself to decisions and actions that are driven from awareness and compassion, rather than choices based within a pro-self orientation. When Jennifer switched parts to support her group, she demonstrated flexibility and empathy to help her group's music composition progress as a whole.

Self-awareness and self-management are competencies that relate to emotional capabilities. The children's comments concerning the part of the creek that speaks to their heart depicts them being self-aware. Learning experiences like these can facilitate the surfacing of underlying emotions, values, and motivations to assist in the development of self-awareness. At the same time, self-management is addressed through Carrie's explanation of how adults can help children improve their communication skills and better negotiate their differences. This competency emerged vividly during the first visit to the creek, as some of the children struggled to hear the water because their peers were talking and unable to self-manage. Over the course of the inquiry, engagement in contemplative practices allowed the students to foster more reflective versus reactive responses to the experience-like being quiet while listening, or having to negotiate their ideas in co-constructivist situations. When children are in a reflective state, they are better able to notice and handle difficult emotions and persevere towards goals.

There is value in movement and music as a means to develop the competencies of social awareness and relationship skills. The livingness that resides in both art forms empowered the children to reflect on bringing life to their understandings in a way that enabled others to hear, feel, and perceive what they experienced at the creek. While doing so, they had to simultaneously observe and interpret group members' music and movement ideas, discover how to orchestrate those ideas together, and find their own function and role within the group. For instance, Steve's attempt to create watery waves by rippling the blue fabric with Nicole took a fair bit of time and patience. They both had their own ideas of how the ripples should be performed, as their arms moved at two different tempos-one wanted fast, short waves and the other wanted big, slow waves. The abstract nature of the rippling waves provided them with an opportunity to reflect, negotiate, and coordinate to develop an understanding of each other's 
ideas. Thus, by learning to look through multiple perspectives, young learners can help build bridges to connect, heal, and empower themselves amongst peers.

Although SEL and mindfulness have thus far been examined separately to identify and reflect on key traits, they do harmonize together. For instance, mindfulness was able to allow for meaningful inner self-exploration by facilitating the surfacing of underlying emotions, values, and motivations. During one session, Nicole contemplated over singing her musical composition, and she initially chose not to sing based on how she felt others would perceive her singing abilities. In providing a safe and exploratory learning environment, the students were able to revisit their music and movement pieces time and time again. As the project progressed, Nicole was able to explore, try, and change her part within her group. She began cultivating her own conclusions about her capabilities and, in turn, utilized her skillsets with confidence towards the end of the project. Through the symbiotic relationship between SEL, mindfulness, and the performing arts, we were able to empower the children to reflect and illuminate their emotions and feelings in music and movement compositions. We also found that learning these concepts in tandem led to a heightened sensitivity to listening, as students embraced listening as a way of welcoming others and their differences. As the students engaged in a manner of reciprocal listening, they were able to represent their theories and interpretations through music and movement. By doing so they were also able to offer their peers the possibility of becoming part of their theories, developments, and thoughts (Rinaldi, 2004, p. 4).

\section{A Heartfelt Coda}

Through the arts children can begin to learn to see what they had not yet noticed, to feel what they had not yet felt, and to employ forms of thinking that are not only indigenous to the arts, but also to their emotional and behavioral development (Eisner, 2002, p. 12). There is great value in providing artful learning experiences that center on mindful learning and the development of SEL. A commitment to guiding those concepts through the performing arts not only allows for successful performances, but can also foster self-esteem, self-confidence, determination, and emotional expression. With that in mind, there is still minimal research on SEL and mindfulness in the performing arts. In our study, we only explored music and movement. Due to limitations, we were unable to include drama. Furthermore, there is research to be conducted with meta-communication as mindfulness-in-action in the performing arts, as the abstract nature of movement and music is a powerful tool that can enable children to develop a meta-communicative toolbox to assist them through artistic impasses.

Eisner (2002) posits,

The arts are means of exploring our own interior landscape. When the arts genuinely move us, we discover what it is that we are capable of experiencing. In this sense, the arts help us discover the contours of our emotional selves. They provide resources for experiencing the range and varieties of our responsive capacities. (p. 11)

It was evident that as the students developed a deeper understanding of their capabilities through self-discovery and exploration, the compositions that they were creating also began to reflect an 
increased sophistication and creative use of sound and movement. We believe that it is important to not only promote the necessary tools and practices for young learners to succeed in the arts, but to also develop their well-being as artists. Being successful in the performing arts means more than partaking in an experience-it entails the development of empathy, passion, understanding, and, above all, imagination that enables children to particularize, to see and hear things in their concreteness. If imagination is to transcend and transform experience for young learners, it has to question, to challenge, to conceive of alternatives, perhaps to the very life they live. Maxine Greene (1995) suggests,

To tap into imagination is to become able to break with what is supposedly fixed and finished, objectively and independently real...Doing so, a person may become freed to glimpse what might be, to form notions of what should be and what is not yet. (p. 19)

As educators we need to see beyond to carve out anew. We need to provide meaningful learning experiences that empower children to not only engage in the present moment and make novel distinctions, but also foster a social and emotional skillset while doing so. Learning experiences that allow for imagination can support children to steer clear of fixed mind-sets and develop those that are flexible and open. By doing so, we can support children to make novel distinctions through intense focus, reflection, and transformation. Inviting students to use their imagination means inviting them to see things other than the way they are. And, of course, this is what art educators do; they scaffold their students to perceive what is, imagine what might be, and then use their knowledge and artistic skills to pursue what they have imagined (Eisner, 2002).

\section{References}

Abram, D. (1996). The spell of the sensuous: Perception and language in a more-than-human world (1st ed.). Pantheon Books.

Bateson, G. (1976). A theory of play and fantasy. In J. Bruner, A. Jolly, \& K. Sylva (Eds.), Play, its role in development and evolution (pp. 119-129). Penguin.

CASEL. (Collaborative for Academic, Social, and Emotional Learning). (2003). Effective social and emotional learning programs. KSA-Plus Communications.

Croom, A. M. (2012). Music, neuroscience, and the psychology of well-being: A précis. Frontiers in Psychology, 2(393). doi:10.3389/fpsyg.2011.00393

Denham, S., Brown, C., \& Domitrovich, C. (2011). 'Plays nice with others': Social-emotional learning and academic success. Early Education and Development, 21(5), 652-680.

Eisner, E. W. (2002). The arts and the creation of mind. Yale University Press.

Ellis, C. (2004). The ethnographic I: A methodological novel about autoethnography. AltaMira Press.

Ellis, C., \& Bochner, A. P. (2000). Autoethnography, personal narrative, reflexivity: Researcher as subject. In N. K. Denzin and Y. S. Lincoln (Eds.), The handbook of qualitative research (2nd ed., pp. 733-768). Sage. 
Gouzouasis, P., \& Ryu, J. Y. (2015). A pedagogical tale from the piano studio: Autoethnography in early childhood music education research. Music Education Research, 17(4), 397-420.

Gouzouasis, P., \& Yanko, M. (2018a). Reggio's arpeggio: Becoming pedagogical through autoethnography. In W. Parnell \& J. M. Iorio (Eds.), Disrupting early childhood education research: Imagining possibilities (pp. 56-70). Routledge.

Gouzouasis, P., \& Yanko, M. (2018b). Learning stories and Reggio Emilia-inspired: Formative methods of assessment for the elementary school music classroom. In P.P. Trifonas \& S. Jagger, (Eds.), Handbook of cultural studies and education (pp. 486-502). Routledge.

Greene, M. (1995). Releasing the imagination. Jossey-Bass Publishers.

Greene, M. (2001). Variations on a blue guitar: The Lincoln Center Institute lectures on aesthetic education. Teachers College Press.

Hallam, S. (2010). The power of music: Its impact on the intellectual, social and personal development of children and young people. International Journal of Music Education, 28(3), 269-289.

doi:10.1177/0255761410370658

Jacobi, B. S. (2012). Opportunities for socioemotional learning in music classrooms. Music Educators Journal, 99(2), 68-74. doi:10.1177/1048371309349569

Kabat-Zinn, J. (2003). Mindfulness-based interventions in context: Past, present, and future. Clinical Psychology: Science and Practice, 10, 144-156.

Laban, R. (1963). Modern educational dance (rev. 2nd ed.). MacDonald and Evans.

Langer, E. J. (2000). Mindful learning. Current Directions in Psychological Science, 9(6), 220-223. doi:10.1111/1467-8721.00099

Langer, E. J. (2016). The power of mindful learning. Da Capo Lifelong Books.

Langer, E. J., Russell, T., \& Eisenkraft, N. (2009). Orchestral performance and the footprint of mindfulness. Psychology of Music, 37(2), 125-136. doi:10.1177/ 0305735607086053

Lawlor, M. S. (2016). Mindfulness and social emotional learning: A conceptual framework. In K. A. Schonert-Reichl, \& R. W. Roeser (Eds.), Handbook of mindfulness in education (pp. 65-80). Guilford.

Lockford, L. (2002) Interlude: Breaking habits and cultivating home. In A. Bochner \& C. Ellis (Eds.), Ethnographically speaking: Autoethnography, literature, and aesthetics (pp. 76-86). Altamira Press.

Lund, N. L. ,\& Kranz, P. L. (1994). Notes on emotional components of musical creativity and performance. The Journal of Psychology, 128(6), 635-640. doi:10.1080/00223980.1994.9921291

Malaguzzi, L. (1998). History, ideas and basic philosophy: An interview with Lella Gandini by Loris Malaguzzi. In C. Edwards, L. Gandini, \& G. Forman (Eds.), The hundred languages of children: Advanced reflections (pp. 49-98). Ablex.

Pereira, N. S., \& Marques-Pinto, A. (2018). Development of a social and emotional learning program using educational dance: A participatory approach aimed at middle school students. Studies in Educational Evaluation, 59, 52-57. doi:10.1016/j.stueduc.2018.03.003 
Pinniger, R., Brown, R. F., Thorsteinsson, E. B., \& McKinley, P. (2012). Argentine tango dance compared to mindfulness meditation and a waiting-list control: A randomised trial for treating depression. Complementary Therapies in Medicine, 20(6), 377-384. doi:10.1016/j.ctim.2012.07.003

Rinaldi, C. (2004). The relationship between documentation and assessment. Innovations in Early Education: The International Reggio Exchange, 11(1), 1-4.

Rooney, R. (2004). Arts-based teaching and learning: Review of the literature. VSA Arts.

Snowber, C. (2019). Embodied perspectives on creativity, inquiry, and research. In C. Mullen (Ed.), Creativity under duress in education? Creativity theory and action in education, volume 3 (pp. 201-214). Cham, CH: Springer.

Truax, B. (2008). Soundscape composition as global music: Electroacoustic music as soundscape. Organised Sound, 13(2), 103-109.

Weissberg, R. P., Payton, J. W., O'Brien, M. U., \& Munro, S. (2007). Social and emotional learning. In F. C. Power, R. J. Nuzzi, D. Narvaez, D. K. Lapsley, \& T. C. Hunt (Eds.), Moral education: A handbook, Volume 2: M-Z (pp. 417-418). Greenwood Press.

Yanko, M. (2019). Learners' identity through soundscape composition: Extending the pedagogies of Loris Malaguzzi with music pedagogy. LEARNing Landscapes, 12(1), 271-284.

Yanko, M., \& Gouzouasis, P. (2019). Storied assessment of the aesthetic experiences of young learners. In P. P. Trifonas (Ed.), Handbook of theory and research in cultural studies and education. Springer International Publishing. Retrieved from https://doi.org/10.1007/978-3-030-01426-1_61-1

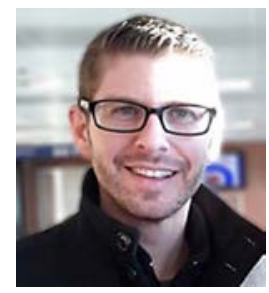

Matt Yanko is a doctoral candidate and instructor in the Department of Curriculum and Pedagogy at the University of British Columbia. Under the supervision of Professor Peter Gouzouasis, his research focuses on formative assessment practices in arts education. Inspired by the early childhood centers of Reggio Emilia, Matt has adapted this approach to his elementary school music classroom, which has inspired the creation of a musical atelier for his students to participate in music making, learning, and inquiry.

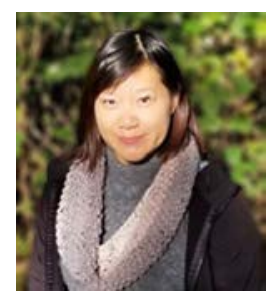

Priscilla Yap has been teaching at the elementary level for 15 years in British Columbia. She holds both a Bachelor of Arts degree in Psychology and Sociology, and a Bachelor of Education degree, specializing in Early Learning and Development from the University of British Columbia. Over the last seven years, she has been involved in many District and Ministry initiatives, workshops, and presentations representing and advocating for the transformation of education, curriculum, assessment, and reporting for early learners. 